\title{
The impact of macroeconomic news on Bitcoin returns
}

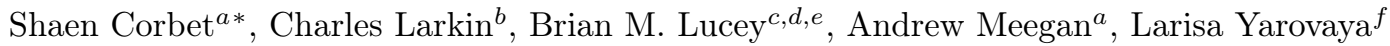 \\ ${ }^{a}$ DCU Business School, Dublin City University, Dublin 9, Ireland \\ ${ }^{b}$ Institute for Policy Research, University of Bath, UK \\ ${ }^{c}$ Trinity Business School, Trinity College Dublin, Dublin 2, Ireland \\ ${ }^{d}$ Institute of Business Research, University of Economics Ho Chi Minh City, Ho Chi Minh City, Vietnam \\ e University of Sydney Business School, Sydney, New South Wales, Australia \\ ${ }^{f}$ Southampton Business School, University of Southampton, Southampton, UK \\ *Corresponding Author: shaen.corbet@dcu.ie
}

\begin{abstract}
This paper examines the relationship between news coverage and Bitcoin returns. Previous studies have provided evidence to suggest that macroeconomic news affects stock returns, commodity prices and interest rates. We construct a sentiment index based on news stories that follow the announcements of four macroeconomic indicators: GDP, unemployment, Consumer Price Index (CPI) and durable goods. By controlling for a number of potential biases we determine as to whether each of the series' have a significant impact on Bitcoin returns. While an increase in positive news surrounding unemployment rates and durable goods would typically result in a corresponding increase in equity returns, we observe the opposite to be true in the case of Bitcoin. Increases in positive news after unemployment and durable goods announcements result in a decrease in Bitcoin returns. Conversely, an increase in the percentage of negative news surrounding these announcements is linked with an increase in Bitcoin returns. News relating to GDP and CPI are found not to have any statistically significant relationships with Bitcoin returns. Our results indicate that this developing cryptocurrency market is further maturing through interactions with macroeconomic news.
\end{abstract}

Keywords: Cryptocurrencies; Macroeconomic News; Return Volatility; Sentiment.

\section{Introduction}

Much debate has taken place while attempting to classify Bitcoin as a financial instrument, and the shared characteristics between itself and traditional financial products. With respect to this, we 
extend on an approach which has identified a relationship between a number of traditional financial instruments and macroeconomic news to examine as to whether this same relationship is present within the volatility of price returns of Bitcoin. We aim to contribute to the existing debate by providing further evidence with regard to the characteristics of Bitcoin, particularly with respect to other financial market instruments. While much research has analysed the impact of the U.S. macroeconomic news announcements on returns of various financial markets, to date, the response to cryptocurrency markets in the same capacity as other more developed financial markets. Kurov and Stan [2018] examined the market reaction of U.S. macroeconomic announcements on returns of the stock, bond, foreign exchange and crude oil markets, providing evidence supporting the impact of monetary policy uncertainty on the behaviour of investment assets. The results show that the increased uncertainty about the future monetary policy strengthens the response to macroeconomic news for bonds and foreign exchange markets, but weakens the responses of stock and crude oil markets. The influence of U.S. macroeconomic announcements has also been established for the U.S. futures markets (Evans [2011]), options markets (Verousis et al. [2016]), Treasury bond yields (Altavilla et al. [2017]), foreign exchange markets (Faust et al. [2007];), German Bund futures (Hautsch et al. [2011]), and S\&P ETFs (Scholtus et al. [2014]), to name but a few.

Birz and Lott [2011] analysed the impact of news based on macroeconomic variables and their influence on stock prices to find that surprises on their own do not only affect stock returns, but also the manner in which inventors interpret them. These results support the 'policy anticipation hypothesis' generated by Cook and Korn [1991] that postulates that the market participants' reactions to economic news is driven by their expectations of the Federal Reserve's response to the news. Hayo and Neuenkirch [2015] investigated how markets' participants process news from the central banks highlighted that media reports play a key role in the formation of financial market actors expectations', while self-monitoring of the central bank news plays only a secondary role. These results also reveal the issue of the misinterpretation of the policy announcements by the media. The correct interpretation of such news announcements becomes critical if the issues of asymmetry and non-linearity of the impact of economic news on financial assets are taken into consideration (Medovikov [2016]). This is even more important in a digital age where investor's sentiment can be derived from the social media (Renault [2017]; Siganos et al. [2017]), news wires and other internet sources (Sun et al. [2016]).

In the situation of high policy uncertainty, such as that which cryptocurrency markets are 
currently facing, research based on the impact of news on investors' expectations is particularly important to consider. There are two alternative hypotheses that can be tested. Taking into account that cryptocurrencies, such as Bitcoin, Ripple, Ethereum, are new and relatively immature financial markets, they can be highly influenced by the media since they attract substantial attention from investors seeking higher returns. Thus, the returns of these highly speculative assets can be susceptible to macroeconomic news as result of changes in investors' expectations about future policy response. Alternatively, taking into account such possible inefficiency in cryptocurrency markets as reported by Urquhart [2016], cryptocurrency markets can be relatively isolated not only from the shock transmitted from other asset classes (see for example Corbet et al. [2018]) but also demonstrate a weaker response to macroeconomic news announcements in comparison to conventional assets and currencies.

There are some recent papers that shed light on particular aspects of cryptocurrency markets that have motivated us to explore this topic in the context of Bitcoin. For example, Corbet et al. [2019] found evidence that digital assets can be influenced by the US Federal Fund interest rates and quantitative easing announcements, however, the degree of influences varies depend on the type of digital asset and their primarily function (e.g. money or data transfer). Urquhart [2018] analysed the relationships between Bitcoin attention and realised volatility and returns of Bitcoin using Google Trends data and report an absence of predictive power of attention for next day Bitcoin returns. However, the impact of macroeconomic news on Bitcoin returns has not been analysed in the literature yet. According to our best knowledge, and further motivated by the systematic review of cryptocurrency related literature by Corbet et al. [2018], we believe that this paper is the first that provides research based on the volatility generating effect of macroeconomic news and such influence on cryptocurrency returns. The contribution of this paper is threefold, with each of those contributions generating particular novelty in the associated results.

First, in comparison to numerous papers on Bitcoin that recently have been published in finance journals, this paper goes beyond a purely empirical investigation of the data. We attempt to contribute to current theoretical debates on investments sentiments and other behavioural aspects based on the influence of the media on financial markets, using cryptocurrency returns, which are particularly interesting and important for a wide range of investors across the globe. Thus in this paper we particularly emphasise the importance of financial market theory development, which is particularly necessary given that we are still firmly in the early stages of developing cryptocurrency 
research and understanding. Second, we construct a news index, based on the prevailing sentiment of newspaper headlines that were published on the days surrounding macroeconomic announcements. To convert these newspaper headlines to data, we build on the methods proposed in Lott and Hassett [2014]. Headlines are collected on the day of and the day following a macroeconomic announcement. Each headline is then classified in one of four categories: positive, negative, mixed or neutral. This methodology aims to capture the prevailing sentiment regarding the content of the announcement itself. Once classified, the headlines can be then used to construct a news index which can be regressed against Bitcoin returns. Finally, the results of this paper contribute to the literature investigating as to whether cryptocurrency is a medium of exchange or speculative assets. We found that cryptocurrency markets react to macroeconomic news in a similar manner as investment assets, such as commodity markets and futures markets, but not forex markets, which supports the position that currently cryptocurrencies are mainly used as a speculative investment (Baur et al. [2018]).

Due to the fact that a number of potential biases stand to distort the true effect of the announcement content, in this paper we employ a number of rigorous robustness checks. For instance, the manner in which an announcement is interpreted rests largely on the current state of economic conditions. In times of recession, small increases in GDP may be reported more favourably than in times of expansion. To overcome this bias, we include a number of indicator variables based on the current state of the business cycle, as defined by McQueen and Roley [1993]. Similarly, the interpretation of an announcement is strongly influenced by the previous period's announcement. Consequently, we must incorporate a factor into our model which can account for this which we have completed through the addition of a surprise index, based on the consensus estimate and actual value of each announcement. Such a method enables some control for the potential bias of economic conditions.

It has also been argued that media headlines themselves can be biased. For example, Dyck and Zingales [2003] found that newspaper coverage favoured Democratic policies and leaders. While this was proven to be true when investigating stock market returns, we have analysed as to whether the same effects influence cryptocurrency markets given the particularly acute periods of political uncertainty that have been experienced even within their relatively short lifespan. As such, we include an indicator variable to control for this bias. We also note the potential for reverse causation in our study. This suggests that the journalist writing the headline itself, may be influenced by 
the fact that they can observe the market's reaction to the announcement. We control for this potential bias and find no evidence for reverse causation in our study. After taking the above factors into account, we regress Bitcoin returns onto each of the following variables: newspaper sentiment, economic surprises, and the current state of the business cycle. We find that announcements related to both durable goods and unemployment produce statistically significant coefficients. While an increase in positive news surrounding unemployment rates and durable goods would typically result in a corresponding increase in equity returns, we observe the opposite to be true in the case of Bitcoin. Increases in positive news after unemployment and durable goods announcements result in a decrease in Bitcoin returns. Conversely, an increase in the percentage of negative news surrounding these announcements is linked with an increase in Bitcoin returns.

The remainder of this paper is organised as follows: Section 2 discuss the theory and hypotheses development, as well as explain the positioning of this paper in the exiting literature. Section 3 describes our data and methodology. Section 4 presents the results, while Section 5 contains a number of robustness tests. Section 6 examines as to whether there exists a possibility of reverse causation in our results, while Section 7 concludes.

\section{Previous Literature}

The relationships between macroeconomic surprises and Bitcoin returns can be explained through assessment of psychological influences on investors behaviour. Proposed by Nakamoto [2008] Bitcoin has developed as an investment asset that have no association with any higher authority, specific country, tangible asset or firm, and the value of it is based on the security of an algorithm which is able to trace all transaction (Corbet et al. [2019]). Anonymity and decentralisation of cryptocurrency attracted attention from both users and investors, which caused enormous growth of market capitalisation and price of Bitcoin. Corbet et al. [2017] while utilising the bubble identification methodology of Phillips et al. [2011], found clear evidence of periods in which Bitcoin and Ethereum were experiencing bubble phases. Urquhart [2016] investigated the efficiency of Bitcoin using a battery of robustness tests to find that returns are significantly inefficient over their selected full sample, but when dividing the same sample, Bitcoin presented evidence of becoming more efficient. Recent findings by Sensoy [2018] also report that Bitcoin prices both in terms US dollar and euros have become more efficient. Using high-frequency data and permutation entropy, the paper also suggests that the pricing efficiency of Bitcoin is lower at higher the frequency, and 
increasing levels of liquidity are found to have a significant effect on the efficiency of Bitcoin. Although research demonstrated that Bitcoin prices are prone to speculative bubbles, where a high level of scepticism has been expressed by regulators' and the media alike, however, cryptocurrency markets continue to maintain significant popularity amongst investors. Similar research has been conducted on the newly developed Bitcoin futures market (Corbet et al. [2018]; Katsiampa et al. [2019b]; Katsiampa et al. [2019a]).

According to the efficient market hypothesis, investors should respond to policy and media announcements and regularly update their expectations and beliefs about the future price of investment assets. Bekaert et al. [2013] analysed the linkages between risk, uncertainty and monetary policy, identifying evidence of a substantial impact of monetary policy on risk-taking behaviour. Making an assumption that there are both rational and irrational traders currently present in cryptocurrency markets with various degrees of risk aversion, Bitcoin prices should be susceptible not only to changes in economic fundamentals and monetary policy changes, forming rational expectations of investors and pushing prices to their fundamental value (Bahloul et al. [2018]), but also to the media reports, news headlines about macroeconomic policy related changes that can be interpreted by noise traders in unpredictable way. Due to the fact, that cryptocurrencies are highly speculative virtual assets fundamental value of those is very challenging to estimate, we hypothesise that the impact of macroeconomic news announcements on Bitcoin returns could be different from other more mature and efficient markets.

A number of previous studies have focused on the relationship between news coverage and financial markets. Tetlock [2007] measures interactions between the media and the stock market, using newspaper content. Daily newspaper content is extracted from a Wall Street Journal column. The author uses the General Inquirer (GI) programme ${ }^{1}$ to construct a pessimism factor and analyses daily variation in the column, over a 16-year period. This particular column is chosen for a number of reasons, namely, high circulation of the publication itself, a well-established and strong reputation among investors and availability of electronic versions of the text. High media pessimism is found to predict downward pressure on market prices. Unusually high or low pessimism is found to lead to temporarily high market trading volume. The price impact of pessimism is found to be particularly

\footnotetext{
${ }^{1}$ The General Inquirer (GI) is a well-known quantitative content analysis programme used to analyse content. The GI counts the number of words in the chosen source material which fall within various word categories. These categories are contained in the GI's Harvard IV-4 psycho-social dictionary.
} 
large, and slow to reverse itself, in the case of small stocks. This finding is consistent with various sentiment theories linking media content to individual investor behaviour. Such investors are found to own a disproportionate fraction of small stocks. Janssen [2004] explored the relationship between market volatility and the arrival of public information in a number of different financial markets over the period between 1994 through 1998. The results indicate significant effects of specific news categories on the volatility of US stocks, treasury bills, bonds and the US dollar, but these effects vary in both size and duration. Bauer [2007] analysed the impact of short run price trending on the conditional volatility to find that the Trend-GARCH model proves to be superior to alternative models such as EGARCH, AGARCH, TGARCH OR GARCH-in-Mean in replicating the leverage effect in the conditional variance, in fitting the news impact curve and in fitting the volatility estimates from high frequency data. Such research guided our own during model selection. Krãd'ussl and Mirgorodskaya [2017] investigated the impact of media pessimism on financial market returns and volatility in the long run through the construction of a monthly media pessimism indicator by taking the ratio of the number of newspaper articles that contain predetermined negative words to the number of positive words in the headline and in the lead paragraph. The authors find evidence for Granger causality of media pessimism on market performance. Bernardi et al. [2017] investigate the impact of news to predict extreme financial returns using high-frequency data and the creation of basic sentiment indexes are constructed starting from three lists of words defined by historical market news response and by a discriminant analysis. The authors confirm that the inclusion of exogenous information as well as the right specification of the returns' conditional distribution significantly decreases the number of actual versus expected VaR violations towards one. Caporale et al. [2018] investigate the effects of newspaper coverage of macro news on the spread between the yield on the 10-year German Bund and on sovereign bonds in eight countries belonging to the euro area. Results indicate that news volatility has a significant impact on yield spread volatility, the effects being more pronounced in the case of negative news.

Using high-frequency intraday returns volatility data, Cai et al. [2001] examine intraday patterns, volatility persistence and announcement effects in the gold futures market. They examine the effect of 23 regularly scheduled U.S. macroeconomic announcements over a period of 4 years, using data at 5-minute intervals. Employment reports, gross domestic product (GDP), consumer price index (CPI) and personal income are found to have significant effects on returns volatility. The impact of announcements over the entire trading day is found to be small, and the gold market's re- 
action to announcements is found to be significantly smaller than those of the foreign exchange and Treasury bond markets. Elder et al. [2012] use intraday data from 2002 to 2008 to examine the impact of US macroeconomic news announcements on the return, volatility, and volume of gold, silver and copper futures. The news database is constructed by combining 19 different types of macroeconomic announcements, including those relating to Consumer Price Index, Personal Consumption and Unemployment Rate. By using the difference between actual values and consensus forecasts to represent the surprise element of each announcement, the authors identify the most important announcements and trace the persistence of macroeconomic shocks. Macroeconomic news is found to have a strong and instantaneous impact on all three metals. This news effect is found to dissipate quickly, within about 60 minutes of the announcement itself. The metal market itself is found to respond to the announcements in an economically predictable manner. Altavilla et al. [2017] adopted a two-step regression approach capturing the impact of macroeconomic surprises on Treasury bond markets at high and low frequencies. The results show that macroeconomic surprises explain only one tenth of the daily variation in bond yields, while predictive power improves at lower frequencies, explaining up to one fourth of the monthly and one third of the quarterly variation in bond yields. Flannery and Protopapadakis [2002] examine the effect of macroeconomic announcements on stock market returns. Using a GARCH model based on daily equity returns, in which realised returns and conditional volatility are dependent upon seventeen announcements series', the authors measure the impact of these announcements on equity returns data. MMS survey estimates are used to construct the surprise aspect of each announcement. Both nominal and real announcements are identified as risk factors. These include announcements regarding CPI, PPI, Monetary Aggregate (nominal) and Balance of Trade, Employment Report and Housing Starts (real). Popular indicators such as Industrial Production, Personal Income, and Sales are found to have no significant effect on returns. Further, Faust et al. [2007] examined the joint movements of exchange rates and U.S. foreign term structures around macroeconomic announcements. Short-term windows around the announcements themselves are examined over a 14-year time span, using high-frequency data. 10 macroeconomic announcements are sampled, including those regarding the FOMC target Federal Funds rate. The surprise aspect of each announcement is calculated by subtracting the Money Market Services (MMS) median survey expectation from the actual data release. Exchange rate returns are constructed over 20-minute windows, using high-frequency returns data at 5-minute intervals. The returns windows start 5 minutes before the announcement release and end 15 minutes after 
the release. Unexpectedly strong announcements regarding prices or real activity in the U.S. are found to lead to short-run appreciation of the dollar. Joint movements in rates imply that these announcements must also lead to a reduction in the risk premium for holding foreign currency over dollars, a net expected dollar appreciation over the ensuing decade, or a combination of the two.

While investigating the general behavioural aspects of cryptocurrencies, Corbet et al. [2019] examined the reaction of a broad set of digital assets to US Federal Fund interest rates and quantitative easing announcements to find a broad range of differing volatility responses and feedback dependent on the type of cryptocurrency investigated and as to whether the cryptocurrency was mineable or not. Corbet et al. [2019] divided all digital assets into three categories cryptocurrencies, protocols and decentralised apps based on their position within the blockchain stack. The results report the strong volatility spillover transfer from US monetary policy announcements to Currency-based digital assets, while decentralised applications or Protocol-based digital assets remained largely immune to policy spillover transfer. Furthermore, mineable digital assets are more susceptible to monetary policy announcements than non-mineable. According to this classification Bitcoin is a digital cryptocurrency since it's main function is a money transfer. Bitcoin is mineable cryptocurrency, because in order to overcome a 'double-spending' problem each transaction must be cryptographically verified by a network node, or 'miner'. Therefore according to the results by Corbet et al. [2019] Bitcoin returns is susceptible to monetary policy announcements, thus in our paper we also hypothesise that it can be susceptible to the macroeconomic surprises related to GDP, unemployment, and durable goods.

Although Bitcoin can be classified as a digital currency there is a significant debates about the role of this asset in the financial system. Some authors claim that Bitcoin is a currency, while other support the position that Bitcoin is a financial asset. Baur et al. [2018] analysed whether various properties of Bitcoin using daily data from July 2010 to June 2015 and found them very different from the traditional asset classes including currencies. However, the analysis of the transaction data of Bitcoin accounts demonstrate that Bitcoin is not an alternative currency but a speculative asset. In this paper, if we assume that Bitcoin is an investment asset, then our hypothesis that macroeconomic news impact Bitcoin return seems logical, since previous literature discussed above provided a good rationale to this statement. However, taking findings of Baur et al. [2018] and Corbet et al. [2018] into account, we also can expect that patterns of these dependencies would be different from traditional assets. This study closely follows the work of Birz and Lott [2011]. 
We specifically investigate four key hypotheses directly relating to the interactions between Bitcoin returns and macroeconomic news, focusing on the following four hypotheses:

- $H_{1}$ : News announcements relating to GDP has a statistically significant effect on the price returns of Bitcoin

- $H_{2}$ : News announcements relating to unemployment has a statistically significant effect on the price returns of Bitcoin

- $H_{3}$ : News announcements relating to the Consumer Price Index (CPI) has a statistically significant effect on the price returns of Bitcoin

- $H_{4}$ : News announcements relating to durable goods has a statistically significant effect on the price returns of Bitcoin

Using newspaper stories as a measure of macroeconomic news, Birz and Lott [2011] found evidence to suggest that GDP and unemployment related news affects stock returns. Macroeconomic news has been shown to affect stock prices by influencing investors' expectations regarding future economic activity, and ultimately, cash flows. Having selected four macroeconomic variables (GDP, unemployment, retail sale, and durable goods) the authors then construct a news index, representing the daily sentiment contained within newspaper articles, with regard to each of the macroeconomic variables. Their findings suggest that it is not purely surprises which affect returns, but also the way in which these surprises are interpreted by investors. While GDP and unemployment are found to significantly affect stock returns, durable goods and retail sales are found to be insignificant. The authors comment that there may be a number of additional macroeconomic variables which may affect stock prices.

\section{Data \& Methodology}

\subsection{Data}

Bitcoin is traded internationally, on a large number of third party exchanges. As such, there is no one consensus price at any fixed point in time. In this study, Bitcoin closing prices are sourced from coindesk.com using their Bitcoin Price Index (BPI). This index is calculated by taking the simple average of the price of Bitcoin on a number of leading exchanges. In this manner, our data better represents the state of the entire Bitcoin market. 
Table 1 contains summary statistics which compare the daily percentage change in the Bitcoin Price Index to a traditional financial index (the S\&P 500). The daily closing price is used for the S\&P 500, while the comparative Bitcoin price at the same time at which the closing stock market index is taken. Bitcoin prices exhibit a number of unique characteristics when compared with traditional financial returns data. Daily price changes of over $50 \%$ are observed in our sample of Bitcoin returns, compared with a maximum change in S\&P returns of $6.7 \%$. The average daily relative change in Bitcoin returns is $3.4 \%$. This figure can be compared to the traditional S\&P 500 index, over the same period, which has an average daily price change of $0.6 \%$. Furthermore, the standard deviation of returns is significantly greater in the case of Bitcoin (4.9\%) when compared to the S\&P $500(0.7 \%)$.

\section{Insert Table 1 about here}

Bitcoin returns are clearly significantly more volatile when compared with those of traditional financial markets. This significant increase in daily price changes can be explained by the fact that the Bitcoin market is still relatively new and continues to grow, with more and more new participants entering the market daily. The Bitcoin market is also highly speculative, attracting large numbers of day traders. Because the Bitcoin market does not possess the size or liquidity of established markets like the $\mathrm{S} \& \mathrm{P} 500$, these speculative traders can exert a greater influence over the market. Finally, the combination of highly speculative market participants (many of whom view Bitcoin as a 'get-rich-quick' scheme) and relatively low levels of liquidity, means that negative news stories or even rumours can prompt a market-wide panic and result in large-scale sell offs. Such events occur relatively frequently, due to the aforementioned lack of liquidity in the market.

We follow the methodology of Lott and Hassett [2014] in classifying newspaper headlines. The authors use the LexisNexis database to collect data on newspaper articles and then analyse these headlines on the day of, and day following, the macroeconomic announcement itself. Newspaper and wire service articles in all of the newspapers in the LexisNexis files and the top ten newspapers were examined for the day of and the day after the news announcement ${ }^{2}$. Our sample incorporates

\footnotetext{
${ }^{2}$ In a similar manner to Lott and Hassett [2014], we include their selected top ten sources which were found to be USA Today, Wall Street Journal, New York Times, Los Angeles Times, Washington Post, New York Daily News, New York Post, Chicago Tribune, Newsday, and Houston Chronicle. We also include that of the Financial Times, The Guardian (UK edition), Bloomberg and Reuters newswires.
} 
the period between 19 July 2010 and 30 September 2019. The headlines had to either directly or indirectly allude to economic data that were released either that day or the day before. In all, 3,831 headlines are included in the analysis To be included in the sample, a headline must explicitly acknowledge the release of the economic announcement itself. We chose headlines because they create the strongest image of the news in readers' minds, and because headlines are easier to objectively classify, though the headlines we examine may differ systematically from the stories they are associated with. As in Lott and Hassett [2014], we classify the headlines into one of four categories, based on the prevailing sentiment of the article itself. The four categories are as follows: positive, negative, neutral, and mixed. We utilise similar rules to that used by Lott and Hassett [2014] when identifying and classifying newspaper headlines. For the LexisNexis search, we use search term rules where we first focus on terms such as 'gross domestic product,' 'unemployment,' 'durable goods,' and 'consumer price'. We first read the headlines and code and if the headline is on the day of the report, make sure the article mentions the current figures or report. This method is also supported methodologically using R-studio to add robustness based on the timestamps. Finally, the headline must refer to the release of the current report or economic condition in some manner. We omit results that contain vague parameters with no timestamp. We then implement a number of pre-established classifying headlines. For example, if the headline said 'unemployment was increasing' or 'durable goods/retail sales/GNP was decreasing' (or some variation of this), that is coded as negative news. The opposing statements would therefore be considered to consider of positive news. Increase levels of consumer spending, consumer confidence, sales, income, manufacturing and the number of jobs is considered to be positive news. Increased inflation and interest rates are considered to be negative news. General adjectives are also separated when referring to the state of the economy. Terms such as optimism, strong, good news, boost, robust and improve, are all found to indicate positive sentiment, while terms such as pessimism, fear, caution, weak, downturn and sceptical all refer to negative sentiment. If there is a positive aspect to the headline and a negative aspect to the headline, it was coded as mixed news. Headlines that dealt exclusively with state numbers were excluded from the data, and the classification is based upon national discussion. Daily summary statistics for the sample of news stories are presented in Table 2. These include the average number of all new stories published, as well as the average number of positive, negative, neutral and mixed stories. For example, on an average unemployment announcement day, there are 18.94 articles that directly reference this macroeconomic news. Of this total, 8.26 are deemed 
to be positive in nature, 5.07 are negative, 1.27 have no prevailing sentiment and are deemed to be neutral, and 4.33 are mixed, containing both positive and negative sentiment.

\section{Insert Table 2 about here}

To determine the net effect of the economic news, we follow the methodology of Lott and Hassett [2014] in constructing a news index. The authors use the University of Michigan Consumer Sentiment Index response method to calculate this index. To construct our index, we express the amount of positive and negative news stories contained within our sample, as a percentage of the total news stories. The percentage of negative stories is then subtracted from the percentage of positive stories, and 100 is added to remove negative values. The daily news indices for each macroeconomic factor, from all newspapers, are summarised in Table 3. A News Index of 200 represents the highest possible level of positive sentiment on a given day. Meanwhile, an index of 0 indicates that any articles released on that day were entirely negative in sentiment. In addition to this index, Lott and Hassett [2014] also examine the net effect of positive and negative news separately. To do this, we regress Bitcoin returns separately, on the percentage of negative and positive stories.

\section{Insert Table 3 about here}

Not all variables in our dataset are covered equally by newspapers. In the case of GDP and unemployment, the average daily number of stories is 13.16 and 18.94 respectively. We assume newspaper coverage represents the interpretation of statistical releases, and we observe there to be less than half as many stories focused on retail sales and durable goods. This finding suggests that more importance is placed upon the release of GDP and unemployment announcements, and as such, these announcements have a larger effect on investors' expectations regarding future economic conditions.

Reverse causation is identified as a potential weakness in the above methodology. The authors suggest that journalists writing stories regarding a macroeconomic release at the end of the announcement day, will have already had the chance to observe the reaction of the market (S\&P 500 closing price) to the release itself. In this manner, any headlines written may be influenced by 
the market reaction itself. To overcome this issue, we compare the relationship between Bitcoin activity on the days of economic releases and the number of subsequently published stories. Birz and Lott [2011] theorise that, if journalists are influenced by market activity, then there should be an increase in the number of articles written about a release, following days which have increased amounts of market activity. A positive, statistically significant relationship between absolute value of Bitcoin returns and the number of macroeconomic news stories, would indicate that this is indeed the case. If there is no correlation between market activity and the number of stories, then it can be concluded that it is indeed the news which is affecting market prices. As previously mentioned, we observe a significantly larger number of stories regarding GDP and unemployment in our sample. If this increased volume does indicate that GDP and unemployment releases are more important in understanding economic activity, then the market price effect should be significantly stronger for unemployment and GDP than for retail sales and durable goods. As such, we compare results with regard to the two larger volume indicators, versus CPI and durable goods. A similar relationship among the four variables would suggest that journalists are affected by market activity and would indicate the likely presence of reverse causation.

\subsection{Methodology}

Our model to examine the effect of macroeconomic news on Bitcoin returns ultimately takes the following form:

$$
\operatorname{Ln}\left(P_{t}\right) / \operatorname{Ln}\left(P_{t-1}\right)=a_{0}+a_{1} X_{1 t}+a_{2} X_{2 t}+D_{w}+\epsilon_{t}
$$

where $P_{t}$ is the closing Bitcoin price on the macroeconomic announcement day and $P_{t-1}$ is the closing Bitcoin price on the day prior to the announcement. Birz and Lott [2011] found that the channel by which macro news could affect stock price returns can be shown through the fundamental definition of the price of a security $P_{t}=E\left[\sum_{t=1}^{\infty} \frac{C_{t+\tau}}{1+k_{t+\tau}}\right]$ where $P_{t}$ is the price of the security at time $\mathrm{t}, C_{t+\tau}$ is the expected future discounting factor that is a function of the risk free interest rate and the risk premium. Macroeconomic news affects stock prices though investor's expectations about future economic activity, because economic conditions can affect cash flows and the discounting factor. Figure 1 presents the daily returns of Bitcoin between 2010 and 2019. $X_{1 t}$ is a newspaper variable representing the News Index or percentages of positive and negative stories, respectively, while $X_{2 t}$ is a measure of economic surprises. $D_{w}$ is a dummy variable representing the days of the 
week and $\epsilon_{t}$ is an error term.

\section{Insert Figure 1 about here}

On macroeconomic announcement days, we regress Bitcoin returns on the News Index, while also controlling for economic surprises in the releases themselves. By controlling for the surprise aspect of the announcement, we aim to demonstrate that the interpretation of these surprises by investors, can also affect Bitcoin returns themselves. To calculate these surprises, we use the methodology outlined in Andersen et al. [2003, 2007]. We calculate the difference between the actual macroeconomic announcement data and the expected values, and then divide this figure by its sample standard deviation. The surprise for announcement $k$ therefore, takes the following form:

$$
S_{k, t}=\frac{\left(A_{k, t}-E_{k, t}\right)}{\sigma_{k}}
$$

Where $A_{k, t}$ is the actual value of the macroeconomic release $k, E_{k, t}$ is the expected value of release $k$ (as distilled in the International Money Market Services median forecast) and $\sigma_{k}$ is the sample standard deviation of $A_{k, t}-E_{k, t}$. Real-time values for each of the four macroeconomic releases were collected. Retail sales, durable goods and unemployment releases occur monthly, while GDP growth rate announcements are made quarterly. Graphical representations of the calculated news indexes are presented in Figures 2 through 5. We use consensus estimates to represent the expected values of each of our four variables. These consensus estimates are collected prior to the release of macroeconomic data. They are constructed by surveying a number of market participants who provide a best estimate of what they predict the announcement figure will be.

\section{Insert Figures 2 through 5 about here}

Bitcoin itself is an emerging market and is traded on a number of third party exchanges. As such, there are many prices and data series' available for Bitcoin returns, at any one time. We choose to use time series data coindesk.com using their Bitcoin Price Index (BPI). In this manner, we feel we are obtaining a more accurate depiction of the true price of Bitcoin. To control for economic surprises that occur at different stages of the business cycle McQueen and Roley [1993] we extend our methodology to the following specification: 


$$
\operatorname{Ln}\left(P_{t}\right) / \operatorname{Ln}\left(P_{t-1}\right)=a_{0}+a_{1} x_{1 t}+a_{2} x_{2 t} L+a_{3} x_{2 t} M+a_{4} x_{2 t} H+D_{w}+\epsilon_{t}
$$

where $p_{t}$ is the Bitcoin closing price on the macroeconomic announcement day, $p_{t-1}$ is the Bitcoin closing price on the day prior to the announcement. $x_{1 t}$ is a newspaper variable, representing either the News Index or the respective percentage of positive and negative news stories. $x_{2 t}$ is a measure of economic surprises, while Low (L), Medium (M) and High (H) indicate the various states of the economy. $D_{w}$ is a dummy variable representing the days of the week, and $\epsilon_{t}$ is an error term.

We opt against the use of intraday returns data for a number of reasons. Andersen et al. [2007] have shown that the impact of macroeconomic surprises is dependent on what stage of the trading day the news is released at. As all of our announcements occur at the same time (8:30am) an attempt to differentiate between their effects, based on time of release, would be ineffective. Additionally, as with Birz and Lott [2011], we are solely interested in examining whether a relationship exists between news coverage and Bitcoin returns, rather than attempting to measure the impact of such announcements.

\section{Empirical Results}

Table 4 examines the relationship between Bitcoin returns and the surprise aspect of the macroeconomic announcements where we regress Bitcoin closing prices on release days on the macroeconomic surprises series. Only GDP rate surprises provide significant results, indicating that only one of the four investigated macroeconomic surprises appear to have power in predicting Bitcoin returns. Table 5 presents the results of specification (3) taking into account the business cycle stages, as defined McQueen and Roley [1993]. Economic stages, or 'regimes', are defined according to the growth rate of the industrial production index. This is then used to identify three stages in the business cycle: High, Medium and Low. We identify each of these three stages and interact these stages with the macroeconomic announcement data. Having done this, we notice a change in the significance of a number of coefficients. Again, the durable goods and CPI coefficients are found not to be significant, indicating that these announcements do not impact Bitcoin returns on the day of the releases themselves. GDP however, displays a strong statistically significant coefficient. This coefficient indicates that advanced GDP announcements have a positive impact of the price of Bitcoin. Unemployment displays a similarly significant coefficient, but with the opposite sign. 
Indicating that unemployment announcements have a negative impact on Bitcoin prices.

\section{Insert Tables 4 and 5 about here}

Table 6 presents results regarding the relationship between newspaper headlines and Bitcoin returns. The news index coefficient for unemployment (-0.048) is found to be negative and statistically significant. We also regress Bitcoin returns on the respective percentages of positive and negative news. Having done this, both unemployment coefficients remain significant. The positive percentage coefficient of -0.091 indicates that Bitcoin returns react negatively to positive unemployment news. The reverse therefore, is to be expected in the case of negative news. The coefficient of 0.070 indicates that this is indeed the case.

\section{Insert Table 6 about here}

The coefficient for durable goods (-0.018) is also found to be significant. Again, we subject this result to robustness tests using the respective percentages of positive and negative news stories. Again, both regressions are found to be significant and have the expected signs. An increase in positive news related to durable goods has a negative effect of Bitcoin returns, while an increase in negative news has the reverse effect. Neither the coefficients for GDP or CPI are found to be statistically significant at the $5 \%$ level, indicating that we can draw no connection between their respective macroeconomic announcements and Bitcoin returns. Table 7 examines the same relationship between Bitcoin returns and newspaper headlines, while also controlling for economic surprises. In this manner, we can examine whether it is both the way surprises are interpreted by investors, as well as the content of the announcements themselves, which affect returns. The results are almost identical to those presented in Table 6. A strong, statistically significant relationship between Bitcoin returns and headlines related to unemployment and durable goods is found. This indicates that the significant effects previously observed in Table 6 are not purely as a result of the surprise aspects of the announcements. Again, GDP and CPI are not statistically significant and are found not to affect Bitcoin returns.

In Table 8, we present the results of a further examination of the relationship between Bitcoin returns and newspaper headlines, while controlling for economic surprises, and also accounting 
for changes in the levels of statistics. Such headlines may only represent a proxy for changes in economic statistics from the previous period. To control for this, we incorporate the changes in each macroeconomic statistic (from one period to the next) into our model and re-estimate the results. After adding controls for changes in all four of our variables, we observe durable goods and the unemployment rate coefficients to remain significantly correlated with Bitcoin returns. Again, both the news index and positive percentage coefficients are negative for both unemployment and durable goods. Both coefficients are again found to be positive in the case of the negative percentage coefficient. This result indicates that, as well as reporting changes in economic statistics, newspaper headlines convey the perception of the news media itself, what they consider important, and the overall significance of economic news in a specific time period.

\section{Insert Tables 7 and 8 about here}

Typically, equity returns are expected to react positively to positive news sentiment. Similarly, a rise in negative news would be expected to result in a decrease in equity returns. We have observed the opposite to be true in the case of Bitcoin. Periods of positivity surrounding macroeconomic announcements are linked to a reduction in Bitcoin returns. Conversely, negativity surrounding these announcements has a positive impact upon Bitcoin returns. Previous studies (Bouri et al. [2017]) have considered the possibility that Bitcoin could act as a form of safe haven asset. The fact that Bitcoin returns increase during times of economic negativity, akin to a flight to safety, presents evidence to suggest that it may be acting as a safe haven instrument. Furthermore, our results provide further evidence to suggest that Bitcoin may be effective when used as a diversification tool.

Bitcoin's status as a cryptocurrency that is advocated for by some investors as a safe haven asset akin to gold which is discussed in Corbet et al. [2018]. In such a context, GDP is seen as a bell-weather for general macroeconomic conditions. The CPI again links back to the idea of Bitcoin as a "gold substitute" whereby increasing inflationary conditions should induce investors in Bitcoin to respond by increasing their investment. The lack of reaction to the CPI may reflect the ongoing problems with the underlying Phillips Curve monetary policy assumption that drives the policy understanding of the link between monetary policy, inflation, unemployment and the inflation as outlined by Chen [2019]. The lack of a hedge response by Bitcoin investors may reflect 
this and requires further investigation. Unemployment is a clear indication of general economic, fiscal and consumer conditions in the economy. More importantly for a hedge, the particular leading indicator of durable goods sales will indicate to investors the possibility of improving or weakening macroeconomic conditions and with that highlight consumer and producer behaviour over a medium-term time horizon. The sensitivity of Bitcoin to this leading indicator therefore should not be surprising.

\section{Robustness Tests}

\subsection{Business Cycle Effects}

Our analysis has so far proven robust to a number of tests. We have examined the relationship between Bitcoin returns and news headlines, while controlling for both economic surprises and changes in levels of statistics. We now perform a number of further analyses. We examine whether business cycle stages have a significant impact on the influence of the surprise aspects of the macroeconomic announcements. We extend our earlier specification to that of equation (3), by incorporating the High, Medium and Low business cycle stages, as defined by McQueen and Roley [1993]. We find significant evidence to suggest that durable goods and unemployment related news continues to affect Bitcoin returns.

\section{Insert Table 9 about here}

While the magnitude of the News Index coefficient for unemployment falls when compared to the results in Table 9 (-0.034), it remains statistically significant at the $5 \%$ level. Similarly, the positive percentage coefficient also falls (to -0.056) but remains significant. In both cases, controlling for different states of the business cycle actually increases the significant levels to 0.031 and 0.033 respectively. The addition of the low, medium and high state effects leads to a loss in significance of the negative percentage coefficient. In the case of durable goods announcements, the addition of business cycle effects results in a News Index coefficient of -0.021. By controlling for business cycle states, the positive percentage coefficient increases in significance (to the $1 \%$ level), indicating that the original coefficients were affected by the business cycle. Finally, we observe the negative percentage coefficient to remain significant, and retain the positive sign that was observed in section 
4. As was the case in our previous regressions, the coefficients relating to GDP and CPI show no significance at any level.

\subsection{Political Bias}

It has been shown [Lott and Hassett, 2014] that newspaper stories related to economic releases are politically biased. The aforementioned study finds newspaper headlines to be more negative when the U.S. President is a Republican. We control for this potential bias in our three news variables (News Index, percentage of positive news, percentage of negative news) by obtaining the residuals from a regression analysis of these news variables and a dummy variable indicating whether the President is Republican or not. After controlling for this political bias, the results of an examination of the relationship between Bitcoin returns and news headlines, are presented in Table 10.

\section{Insert Table 10 about here}

Again, we observe both unemployment and durable goods coefficients to retain significance after the political bias and surprise effects have been controlled for. In the case of unemployment, the magnitude of all three coefficients is similar to those which were observed in our previous sections. However, the addition of a variable to control for political bias has resulted in a large increase in the significance of all three coefficients. In the case of News Index and positive percentage, both are now significant at the $1 \%$ level. The results with regard to durable goods are similar to our earlier sections. After controlling for potential bias, we still find a strong, statistically significant relationship between Bitcoin returns and headlines related to durable goods and unemployment. The fact that they retain significance indicates the presence of a sentiment effect which cannot be accounted for by political bias - or indeed any of the previous robustness variables. Once again, neither GDP nor CPI show any significance.

\section{Reverse Causality}

As previously discussed, in Section 3, we note the possibility that journalists writing about macroeconomic news announcements, will be influenced by market changes in response to the announcement itself, throughout the day. While it is unlikely that a change in Bitcoin price would 
influence a journalist in the same way as an established market index (such as the S\&P 500), the possibility of a bias still exists. Journalists may still be influenced with regard to prevailing sentiment around an announcement. We account for this potential bias by performing a robustness check, as presented in Birz and Lott [2011].

\section{Insert Table 11 about here}

We examine the relationship between market activity, using absolute value Bitcoin returns, and the detrended number of stories surrounding the macroeconomic announcements. We suggest that, should journalists actually be influenced by market activity when writing headlines, then a significant increase in the number of stories written should be observed, following days with large amounts of market activity. We regress the detrended number of stories about each release on the Bitcoin returns, on the day of the release. The results are presented in Table 11, and we find no significant evidence to suggest that Bitcoin returns affect the number of stories written about durable goods and unemployment. Such a finding presents strong evidence against the presence of reverse causality.

\section{Conclusion}

In this paper, we have examined the link between macroeconomic news announcements and Bitcoin returns. Previous studies have drawn links between such news and equity returns, commodities and interest rates. We extend these approaches to determine whether the same relationship is present in the emerging digital assets market. We examine four macroeconomic announcements: GDP, unemployment, CPI and durable goods. We observe news related to durable goods and unemployment to significantly affect Bitcoin returns. News relating to GDP and CPI are found not to have any statistically significant relationships with Bitcoin returns. We previously suggested that announcements which generate the highest volume of news stories, of which GDP and unemployment are examples, are more important when informing investors' expectations of future economic conditions. As such, we would expect these coefficients to demonstrate statistical significance. While significance is present in the case of unemployment, the fact that it is absent in all cases of GDP is somewhat surprising. 
Our paper has a series of policy implications. Market sensitivity to consumer durable announcements indicates that Bitcoin is at once treated by some investors as a hedge, with decreases in Bitcoin returns during positive announcements with respective to unemployment and consumer durables. This behaviour of GDP and the CPI is surprising and requires further investigation. While there is evidence of sensitivity to FOMC announcements as in Corbet et al. [2019], it is important to note that the era of unconventional monetary policy, ultra-low interest rates and low inflation in the advanced economies in conjunction with the disruptive effects of intangibles on traditional macroeconomic statistics requires a reassessment of the behaviour of such macroeconomic statistics as effective measures of economic performance. The sensitivity of macroeconomic statistics to new statistical frameworks and accounting for intangibles as highlighted by Connolly [2017] should give pause when assessed in light of the response by Bitcoin to unemployment and consumer durables announcements. Those macroeconomic indicators being less sensitive to the impacts of unconventional monetary policy, intangibles and statistical redefinition. Further research avenues that will need to be explored relate to the relationship between cryptocurrencies and responsiveness to macroeconomic statistics in the face of ESA 2010 and intangibles and the behaviour of cryptocurrencies in response to the weakening relationship of the Phillips Curve, which is said to be at best on "life support" if not dead in the face of unconventional monetary policy.

Our paper contributes to a new, and quickly expanding, field of research regarding cryptocurrencies and the market for digital assets. We contribute to this growing literature through the identification of a similar link between news announcements and Bitcoin returns. Much research has focused on the attempt to classify Bitcoin as a financial asset and the debate surrounding the characteristics of cryptocurrencies at large, and whether they should be viewed primarily as a store of value or a medium of exchange. Our results suggest that Bitcoin shares similar characteristics

to that of equities, commodities, and interest rates with respect to the influence of macroeconomic factors, further contributing to this discussion.

\section{Bibliography}

Altavilla, C., M. Pagano, and S. Simonelli (2017). Bank exposures and sovereign stress transmission. Review of Finance 21(6), 2103-2139.

Andersen, T. G., T. Bollerslev, F. X. Diebold, and C. Vega (2003). Micro effects of macro an- 
nouncements: Real-time price discovery in foreign exchange. American Economic Review 93(1), $38-62$.

Andersen, T. G., T. Bollerslev, F. X. Diebold, and C. Vega (2007). Real-time price discovery in global stock, bond and foreign exchange markets. Journal of international Economics 73(2), $251-277$.

Bahloul, W., M. Balcilar, J. Cunado, and R. Gupta (2018). The role of economic and financial uncertainties in predicting commodity futures returns and volatility: Evidence from a nonparametric causality-in-quantiles test. Journal of Multinational Financial Management 45, 52-71.

Bauer, C. (2007). A better asymmetric model of changing volatility in stock and exchange rate returns: Trend-garch. European Journal of Finance 13(1), 65-87.

Baur, D. G., K. Hong, and A. D. Lee (2018). Bitcoin: Medium of exchange or speculative assets? Journal of International Financial Markets, Institutions and Money 54, 177-189.

Bekaert, G., M. Hoerova, and M. L. Duca (2013). Risk, uncertainty and monetary policy. Journal of Monetary Economics 60(7), 771-788.

Bernardi, M., L. Catania, and L. Petrella (2017). Are news important to predict the value-at-risk? European Journal of Finance 23(6), 535-572.

Birz, G. and J. R. Lott (2011). The effect of macroeconomic news on stock returns: New evidence from newspaper coverage. Journal of Banking and Finance 35(11), 2791-2800.

Bouri, E., P. Molnár, G. Azzi, D. Roubaud, and L. I. Hagfors (2017). On the hedge and safe haven properties of bitcoin: Is it really more than a diversifier? Finance Research Letters 20, 192-198.

Cai, J., Y.-L. Cheung, and M. Wong (2001). What moves the gold market? Journal of Futures Markets 21(3), 257-278.

Caporale, G., F. Spagnolo, and N. Spagnolo (2018). Macro news and bond yield spreads in the euro area. European Journal of Finance 24(2), 114-134.

Chen, Y. (2019). Inflation, Inflation Expectations, and the Phillips Curve: Working Paper 2019-0\%. Congressional Budget Office. Query date: 2019-10-26 13:15:47. 
Connolly, M. (2017). The expected and unexpected consequences of esa 2010-an irish perspective. Journal of the Statistical \& Social Inquiry Society of ăĂe. 3 cites: https://scholar.google.com/scholar?cites $=637834996772637266 \&$ as_sdt $=2005 \&$ sciodt $=0,5 \& h l=$ en.

Cook, T. and S. Korn (1991). The reaction of interest rates to the employment report: The role of policy anticipation. Economic Review, 3-12.

Corbet, S., C. Larkin, B. Lucey, A. Meegan, and L. Yarovaya (2018). Exploring the dynamic relationships between cryptocurrencies and other financial assets. Economics Letters 165(1), $28-34$.

Corbet, S., C. Larkin, B. Lucey, A. Meegan, and L. Yarovaya (2019). Cryptocurrency reaction to fomc announcements: Evidence of heterogeneity based on blockchain stack position. Available at SSRN: https://ssrn.com/abstract=3073727.

Corbet, S., B. Lucey, M. Peat, and S. Vigne (2018). Bitcoin futuresâĂŤwhat use are they? Economics Letters 172, 23-27.

Corbet, S., B. Lucey, and L. Yarovya (2017). Datestamping the bitcoin and ethereum bubbles. Finance Research Letters.

Corbet, S., B. M. Lucey, A. Urquhart, and L. Yarovaya (2018). Cryptocurrencies as a financial asset: A systematic analysis.

Dyck, A. and L. Zingales (2003). The media and asset prices. Technical report, Working Paper, Harvard Business School.

Elder, J., H. Miao, and S. Ramchander (2012). Impact of macroeconomic news on metal futures. Journal of Banking and Finance 36(1), 51-65.

Evans, K. P. (2011). Intraday jumps and us macroeconomic news announcements. Journal of Banking and Finance 35, 2511-2527.

Faust, J., J. H. Rogers, S.-Y. B. Wang, and J. H. Wright (2007). The high-frequency response of exchange rates and interest rates to macroeconomic announcements. Journal of Monetary Economics 54(4), 1051-1068. 
Flannery, M. J. and A. A. Protopapadakis (2002). Macroeconomic factors do influence aggregate stock returns. The Review of Financial Studies 15(3), 751-782.

Hautsch, N., D. Hess, and D. Veredas (2011). The impact of macroeconomic news on quote adjustments, noise, and informational volatility. Journal of Banking and Finance 35, 2733-2746.

Hayo, B. and M. Neuenkirch (2015). Self-monitoring or reliance on media reporting: How do financial market participants process central bank news? Journal of Banking and Finance 59, $27-37$.

Janssen, G. (2004). Public information arrival and volatility persistence in financial markets. European Journal of Finance 10(3), 177-197.

Katsiampa, P., S. Corbet, and B. Lucey (2019a). High frequency volatility co-movements in cryptocurrency markets. Journal of International Financial Markets, Institutions and Money 62, $35-52$.

Katsiampa, P., S. Corbet, and B. Lucey (2019b). Volatility spillover effects in leading cryptocurrencies: A bekk-mgarch analysis. Finance Research Letters 29, 68-74.

KrÃd'ussl, R. and E. Mirgorodskaya (2017). Media, sentiment and market performance in the long run. European Journal of Finance 23(11), 1059-1082.

Kurov, A. and R. Stan (2018). Monetary policy uncertainty and the market reaction to macroeconomic news. Journal of Banking and Finance 86, 127-142.

Lott, J. R. and K. A. Hassett (2014). Is newspaper coverage of economic events politically biased? Public Choice 160(1-2), 65-108.

McQueen, G. and V. V. Roley (1993). Stock prices, news, and business conditions. The Review of Financial Studies 6(3), 683-707.

Medovikov, I. (2016). When does the stock market listen to economic news? new evidence from copulas and news wires. Journal of Banking and Finance 65, 27-40.

Nakamoto, S. (2008). Bitcoin: A peer-to-peer electronic cash system. 
Phillips, P. C., Y. Wu, and J. Yu (2011). Explosive behavior in the 1990's nasdaq: When did exuberance escalate asset values? International Economic Review 52(1), 201-226.

Renault, T. (2017). Intraday online investor sentiment and return patterns in the u.s. stock market. Journal of Banking and Finance 84, 25-40.

Scholtus, M., D. Van Dijk, and B. Frijns (2014). Speed, algorithmic trading, and market quality around macroeconomic news announcements. Journal of Banking and Finance 38, 89-105.

Sensoy, A. (2018). The inefficiency of bitcoin revisited: A high-frequency analysis with alternative currencies. Finance Research Letters.

Siganos, A., E. Vagenas-Nanos, and P. Verwijmeren (2017). Divergence of sentiment and stock market trading. Journal of Banking and Finance 78, 130-141.

Sun, L., M. Najand, and J. Shen (2016). Stock return predictability and investor sentiment: A high-frequency perspective. Journal of Banking and Finance 73, 147-164.

Tetlock, P. C. (2007). Giving content to investor sentiment: The role of media in the stock market. The Journal of Finance 62(3), 1139-1168.

Urquhart, A. (2016). The inefficiency of bitcoin. Economics Letters 148, 80-82.

Urquhart, A. (2018). What causes the attention of bitcoin? Economics Letters 166, 40-44.

Verousis, T., O. ap Gwilym, and X. Chen (2016). The intraday determination of liquidity in the nyse liffe equity option markets. European Journal of Finance 22(12), 1164-1188. 
Figure 1: Bitcoin price level and daily price volatility (2009-2019)

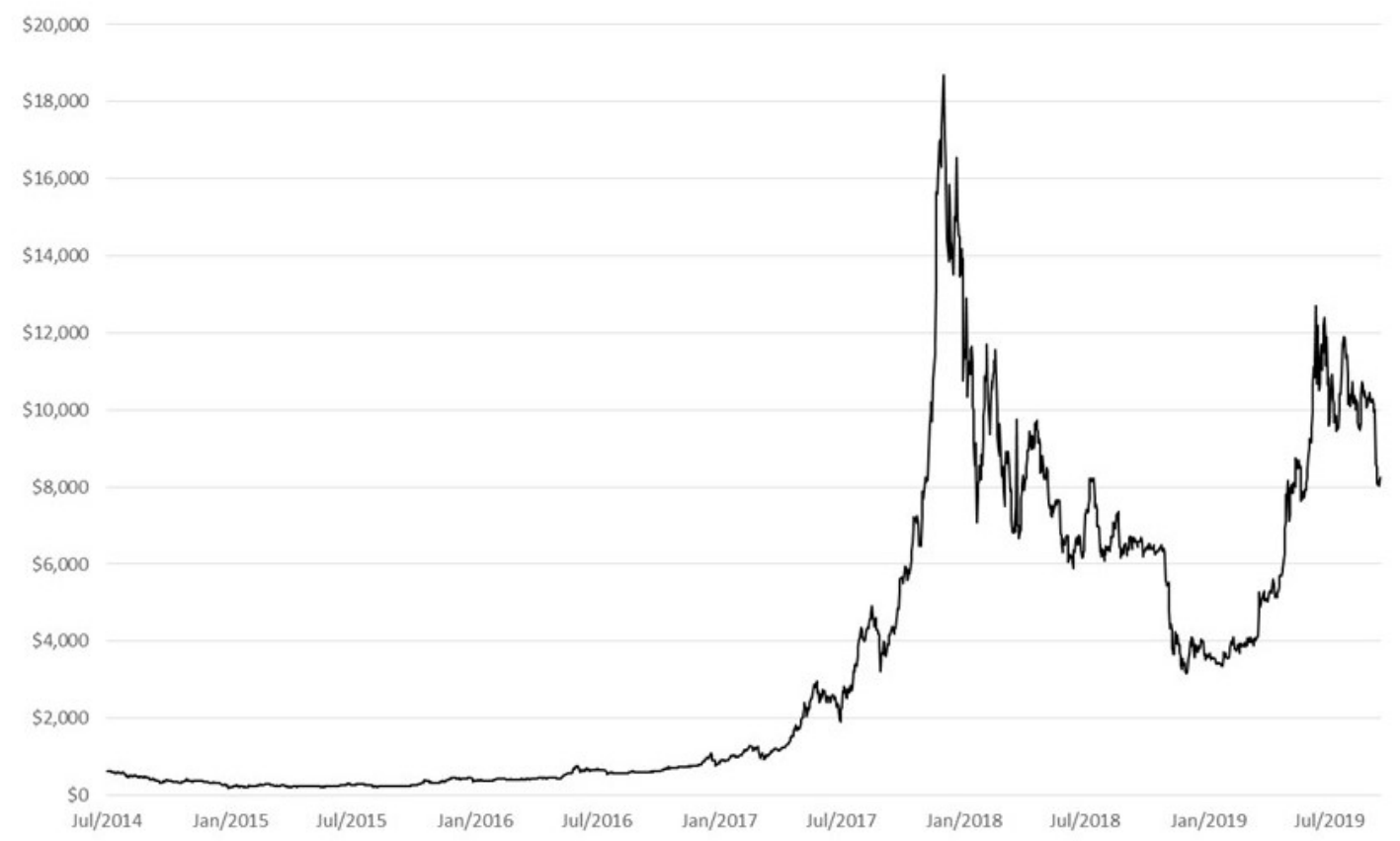

Note: The above panel represents the price of Bitcoin in US\$. The bottom panel represents represents the daily percentage volatility of Bitcoin returns. 
Table 1: Summary Statistics for absolute changes in daily Bitcoin and S\&P 500 returns

\begin{tabular}{lllll}
\hline & Average & Std Dev & Max & Min \\
\hline Bitcoin & 0.031 & 0.043 & 0.529 & 0.000 \\
S\&P 500 & 0.005 & 0.006 & 0.067 & 0.000 \\
\hline
\end{tabular}

Note: Sample data runs from 19 of July 2010 through 30 September 2019.

Table 2: Daily summary statistics for news stories (2010-2019)

\begin{tabular}{|c|c|c|c|c|c|}
\hline & Positive & Negative & Mixed & Neutral & Total \\
\hline \multicolumn{6}{|l|}{ GDP } \\
\hline Average & 4.42 & 3.71 & 2.69 & 2.08 & 12.73 \\
\hline Std. Dev. & 2.72 & 2.90 & 2.24 & 1.39 & 4.02 \\
\hline $\operatorname{Max}$ & 14.00 & 11.00 & 12.00 & 7.00 & 27.00 \\
\hline Min & 1.00 & 0.00 & 0.00 & 0.00 & 6.00 \\
\hline \multicolumn{6}{|c|}{ Unemployment } \\
\hline Average & 7.88 & 4.39 & 4.32 & 1.21 & 14.55 \\
\hline Std. Dev. & 6.41 & 5.72 & 2.61 & 1.52 & 5.76 \\
\hline $\operatorname{Max}$ & 27.00 & 26.00 & 13.00 & 7.00 & 38.00 \\
\hline Min & 0.00 & 0.00 & 0.00 & 0.00 & 2.00 \\
\hline \multicolumn{6}{|c|}{ Durable Goods } \\
\hline Average & 2.70 & 2.16 & 0.65 & 0.21 & 5.81 \\
\hline Std. Dev. & 2.91 & 3.39 & 1.28 & 0.61 & 4.34 \\
\hline $\operatorname{Max}$ & 12.00 & 16.00 & 8.00 & 2.00 & 22.00 \\
\hline Min & 0.00 & 0.00 & 0.00 & 0.00 & 0.00 \\
\hline \multicolumn{6}{|l|}{ CPI } \\
\hline Average & 4.08 & 3.52 & 0.75 & 0.17 & 8.49 \\
\hline Std. Dev. & 3.86 & 3.64 & 2.33 & 0.56 & 6.01 \\
\hline Max & 20.00 & 18.00 & 18.00 & 2.00 & 46.00 \\
\hline Min & 0.00 & 0.00 & 0.00 & 0.00 & 0.00 \\
\hline
\end{tabular}

Note: Daily summary statistics for total number of news stories relating to each of the four variables.

Table 3: Daily summary statistics for our included 'News Index' (2010-2019)

\begin{tabular}{lcccc}
\hline & GDP & Unemployment & Durable Goods & CPI \\
\hline Mean & 107.63 & 118.81 & 113.14 & 106.37 \\
Std. Dev. & 38.79 & 52.04 & 68.27 & 74.73 \\
Max & 190.00 & 193.75 & 200.00 & 200.00 \\
Min & 37.50 & 9.52 & 0.00 & 0.00 \\
\hline
\end{tabular}

Note: Daily summary statistics for News Index of each of the four respective macroeconomic variables. News Index is constructed by subtracting the total percentage of negative stories on an announcement day from the total percentage of positive stories. 100 is added to the result to remove negative values. 
Figure 2: GDP News Index (2010-2019)

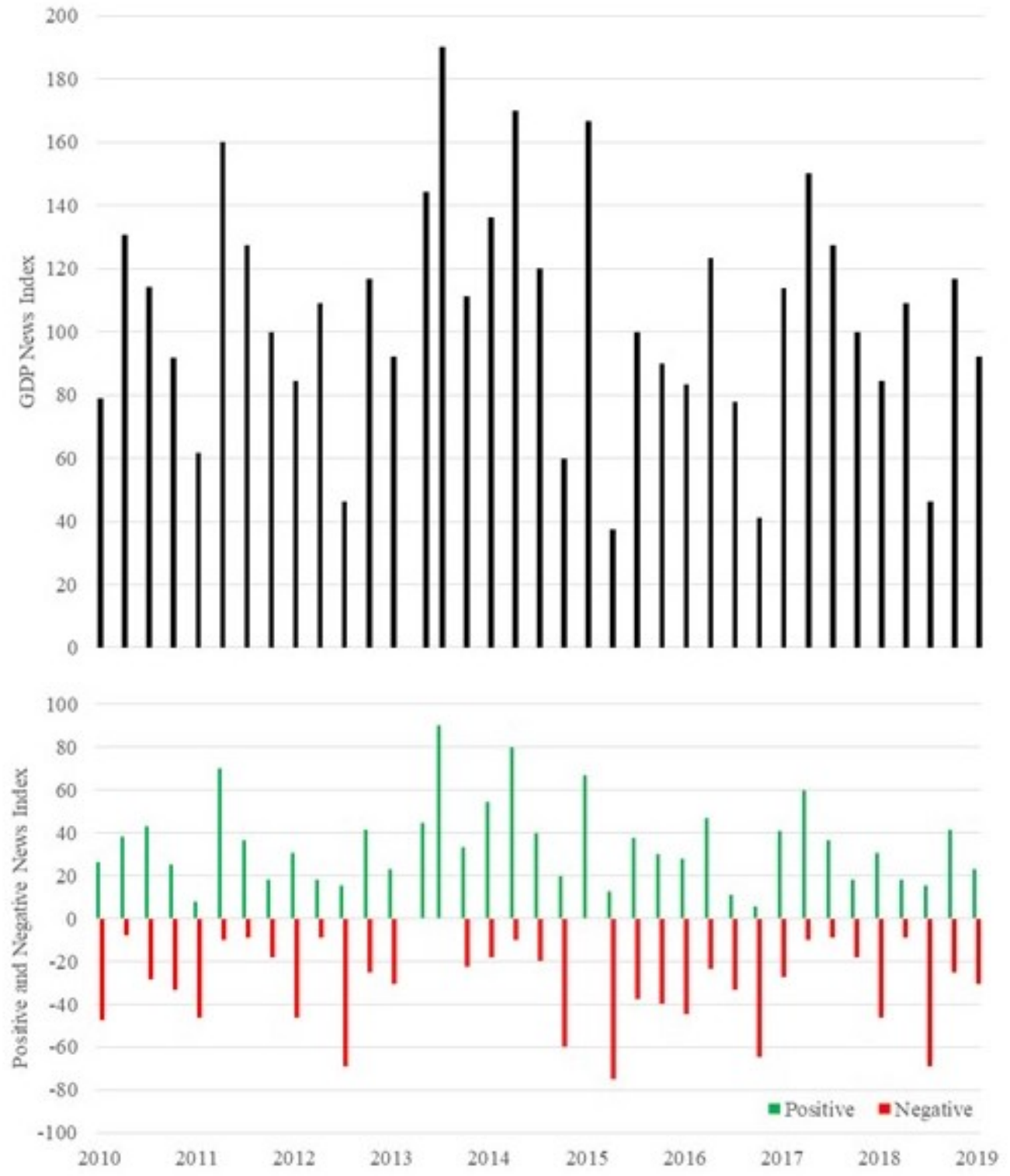

Note: The above panel represents the calculated GDP news index. The bottom panel represents represents separated positive and negative GDP news index components between 2010 and 2019. 
Figure 3: Unemployment News Index (2010-2019)
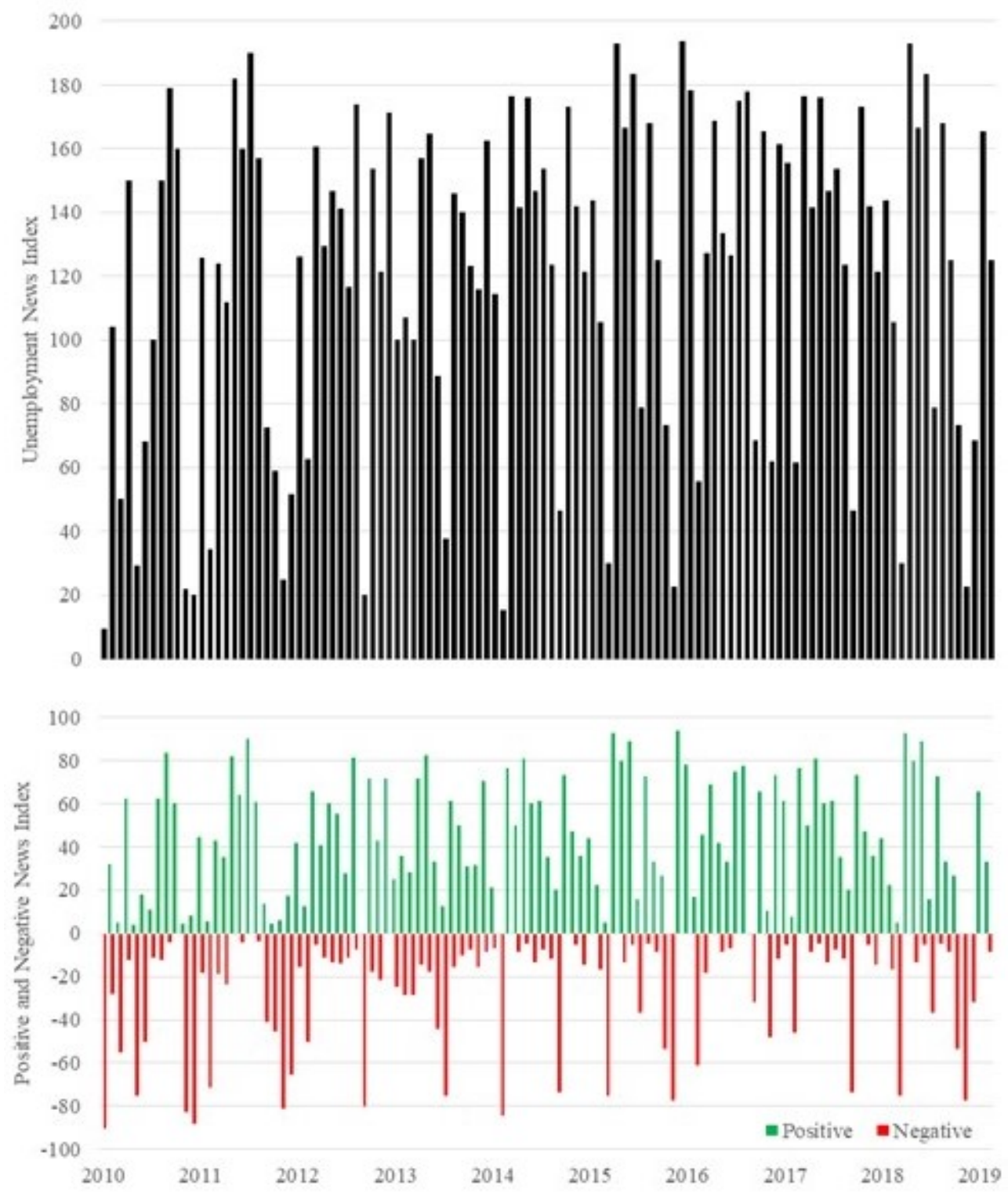

Note: The above panel represents the calculated unemployment news index. The bottom panel represents represents separated positive and negative unemployment news index components between 2010 and 2019. 
Figure 4: Durable Goods News Index (2010-2019)
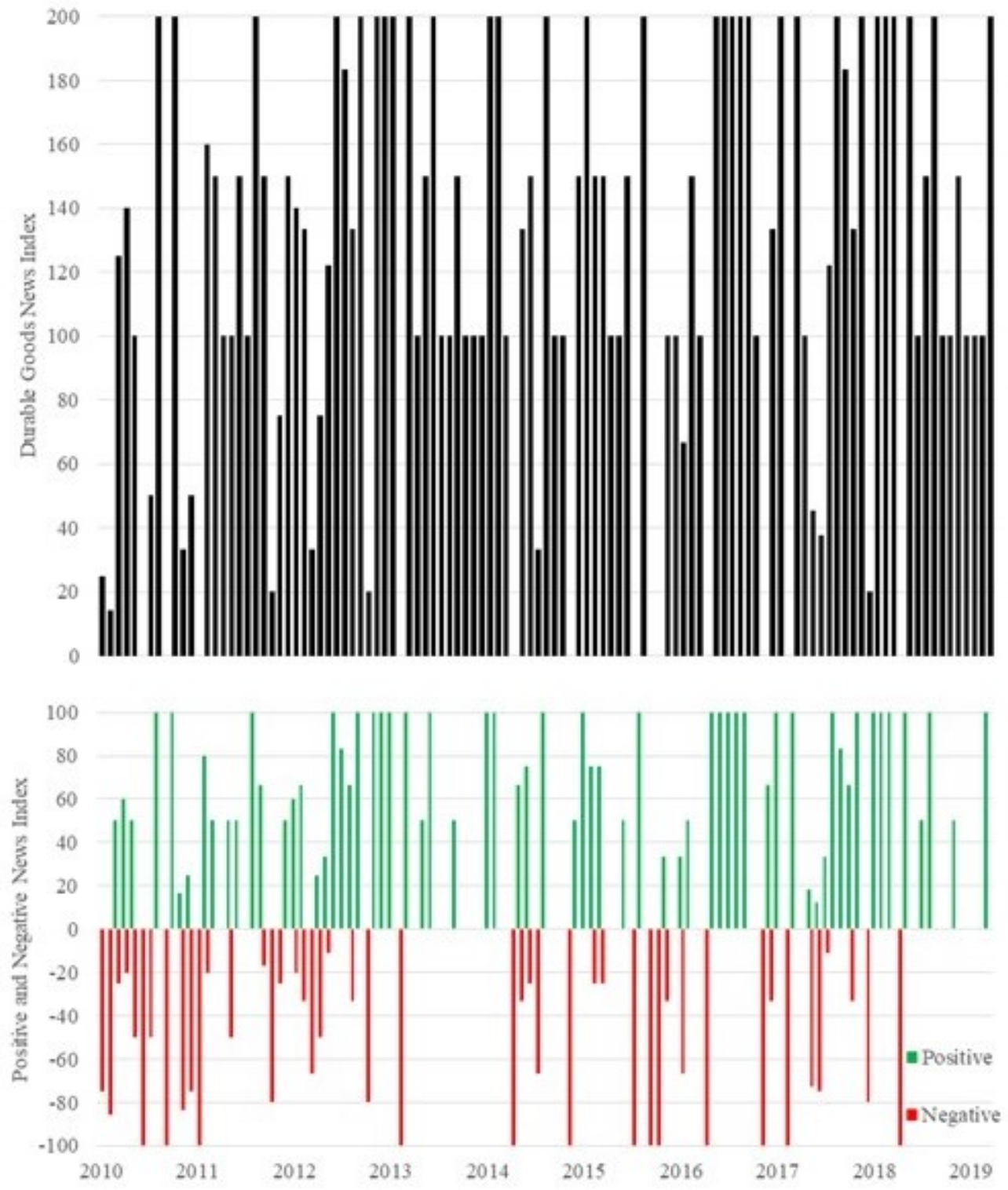

Note: The above panel represents the calculated durable goods news index. The bottom panel represents represents separated positive and negative durable goods news index components between 2010 and 2019. 
Figure 5: CPI News Index (2010-2019)
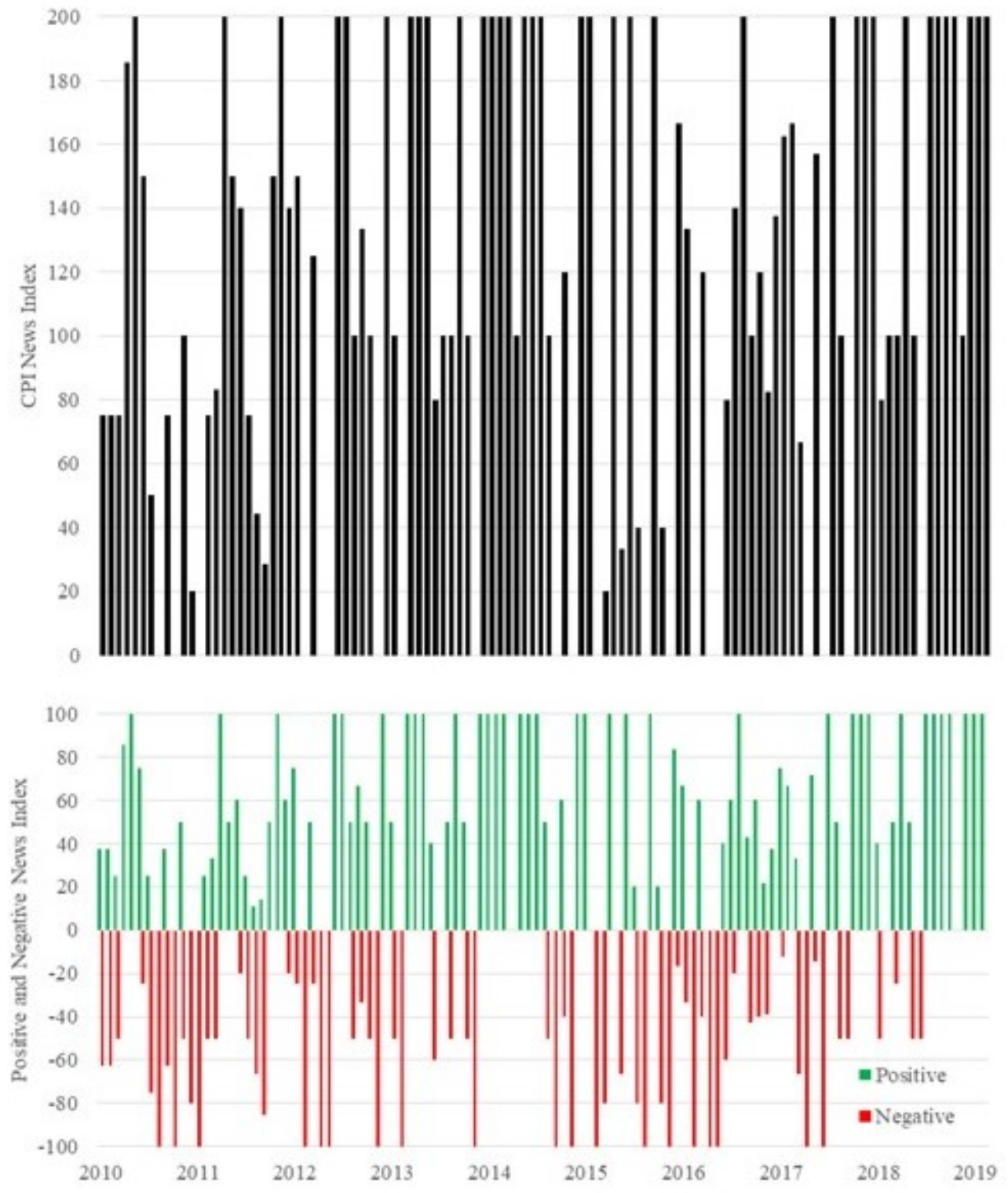

Note: The above panel represents the calculated CPI news index. The bottom panel represents represents separated positive and negative CPI news index components between 2010 and 2019. 
Table 4: The effect of macroeconomic surprises on Bitcoin returns

\begin{tabular}{lcccc}
\hline & Coef. & $\mathrm{N}$ & $r^{2}$ & $\mathrm{~F}$ \\
\hline GDP rate surprise & $1.119^{*}$ & 37 & 0.241 & 3.72 \\
& $(0.947)$ & & & 0.007 \\
Unemployment rate surprise & 0.074 & 110 & & 0.20 \\
CPI rate surprise & $(0.769)$ & 110 & 0.080 & 1.46 \\
Durable goods surprise & $0.653^{*}$ & \multirow{2}{*}{0.029} & 0.62 \\
\hline
\end{tabular}

Note: Percentage changes in the closing price of Bitcoin are regressed against macroeconomic surprises. Regressions include day-of-the-week dummys which are not reported. Coef represents the regression estimates, $\mathrm{N}$ represents the total number of observations while standard errors are presented in parentheses. ${ }^{*}$ denotes significance at the $5 \%$ level; $* *$ denotes significance at the $1 \%$ level; *** denotes significance at the $0.01 \%$ level

Table 5: The effect of macroeconomic surprises on Bitcoin returns, accounting for business cycle effects

\begin{tabular}{|c|c|c|c|c|c|c|}
\hline & Low & Medium & High & $\mathrm{N}$ & $r^{2}$ & $\mathrm{~F}$ \\
\hline GDP rate surprise & $\begin{array}{c}3.871^{* * *} \\
(0.718)\end{array}$ & $\begin{array}{c}-0.674 \\
(0.474)\end{array}$ & $\begin{array}{c}1.286 \\
(0.778)\end{array}$ & 37 & 0.189 & 3.66 \\
\hline Unemployment rate surprise & $\begin{array}{c}-3.062^{* *} \\
(1.282)\end{array}$ & $\begin{array}{l}1.196 \\
(1.000)\end{array}$ & $\begin{array}{c}2.510 \\
(1.653)\end{array}$ & 109 & 0.109 & 2.02 \\
\hline Durable goods surprise & $\begin{array}{c}2.574^{*} \\
(1.378)\end{array}$ & $\begin{array}{c}0.569 \\
(0.755)\end{array}$ & $\begin{array}{c}0.211 \\
(0.701)\end{array}$ & 110 & 0.105 & 1.30 \\
\hline CPI rate surprise & $\begin{array}{l}-1.878 \\
(1.809)\end{array}$ & $\begin{array}{r}-1.646^{*} \\
(0.977)\end{array}$ & $\begin{array}{c}2.038 \\
(1.314)\end{array}$ & 109 & 0.092 & 1.39 \\
\hline
\end{tabular}

Note: Percentage changes in the closing price of Bitcoin are regressed against macroeconomic surprises. Regressions include day-of-the-week dummys which are not reported. Coef represents the regression estimates, $\mathrm{N}$ represents the total number of observations while standard errors are presented in parentheses. ${ }^{*}$ denotes significance at the $5 \%$ level; ** denotes significance at the $1 \%$ level; *** denotes significance at the $0.01 \%$ level 
Table 6: The effect of news stories on Bitcoin returns.

\begin{tabular}{|c|c|c|c|c|c|c|c|c|c|c|c|c|}
\hline & \multicolumn{3}{|c|}{ GDP } & \multicolumn{3}{|c|}{ Unemployment } & \multicolumn{3}{|c|}{ Durable Goods } & \multicolumn{3}{|c|}{ CPI } \\
\hline & $(1)$ & $(2)$ & $(3)$ & $(4)$ & $(5)$ & $(6)$ & $(7)$ & $(8)$ & $(9)$ & $(10)$ & $(11)$ & $(12)$ \\
\hline News Index & $\begin{array}{l}0.038^{*} \\
(0.021)\end{array}$ & & & $\begin{array}{c}-0.048^{* * *} \\
(0.014)\end{array}$ & & & $\begin{array}{c}-0.018^{* * *} \\
(0.007)\end{array}$ & & & $\begin{array}{c}-0.002 \\
(0.010)\end{array}$ & & \\
\hline$\%$ Positive & & $\begin{array}{c}-0.077^{*} \\
(0.041)\end{array}$ & & & $\begin{array}{r}-0.091^{* *} \\
(0.026)\end{array}$ & & & $\begin{array}{r}-0.019^{* *} \\
(0.009)\end{array}$ & & & $\begin{array}{c}0.009 \\
(0.020)\end{array}$ & \\
\hline \%Negative & & & $\begin{array}{l}-0.049 \\
(0.044)\end{array}$ & & & $\begin{array}{c}0.070^{* *} \\
(0.028)\end{array}$ & & & $\begin{array}{c}0.035^{* * *} \\
(0.013)\end{array}$ & & & $\begin{array}{c}0.016 \\
(0.019)\end{array}$ \\
\hline $\mathrm{N}$ & 37 & 37 & 37 & 109 & 109 & 109 & 107 & 107 & 107 & 109 & 109 & 109 \\
\hline$r^{2}$ & 0.24 & 0.25 & 0.21 & 0.08 & 0.09 & 0.06 & 0.13 & 0.09 & 0.15 & 0.02 & 0.02 & 0.03 \\
\hline $\mathrm{F}$ & 3.2 & 3.51 & 2.84 & 2.58 & 2.66 & 1.95 & 1.46 & 1.2 & 1.43 & 0.46 & 0.58 & 0.51 \\
\hline
\end{tabular}

Note: The above panel shows the results of 12 regressions in which the dependent variable is Bitcoin returns. \%Positive and \%Negative represent the respective percentage of each from the collected sample. News Index is calculated as follows: \%Positive - \%Negative +100 . Regressions include day-of-the-week dummys which are not reported. $\mathrm{N}$ represents the total number of observations while standard errors are presented in parentheses. ${ }^{*}$ denotes significance at the $5 \%$ level; ${ }^{* *}$ denotes significance at the $1 \%$ level; $* * *$ denotes significance at the $0.01 \%$ level. 
Table 7: The effect of news stories on Bitcoin returns, controlling for macroeconomic surprises

\begin{tabular}{|c|c|c|c|c|c|c|c|c|c|c|c|c|}
\hline & \multicolumn{3}{|c|}{ GDP } & \multicolumn{3}{|c|}{ Unemployment } & \multicolumn{3}{|c|}{ Durable Goods } & \multicolumn{3}{|c|}{ CPI } \\
\hline & $(1)$ & $(2)$ & $(3)$ & $(4)$ & $(5)$ & $(6)$ & $(7)$ & $(8)$ & (9) & $(10)$ & $(11)$ & $(12)$ \\
\hline News Index & $\begin{array}{c}0.039^{*} \\
(0.020)\end{array}$ & & & $\begin{array}{c}-0.038^{* * *} \\
(0.014)\end{array}$ & & & $\begin{array}{c}-0.018^{* * *} \\
(0.007)\end{array}$ & & & $\begin{array}{l}-0.004 \\
(0.011)\end{array}$ & & \\
\hline \%Positive & & $\begin{array}{l}0.075^{*} \\
(0.040)\end{array}$ & & & $\begin{array}{c}-0.070^{* * *} \\
(0.026)\end{array}$ & & & $\begin{array}{c}-0.019 * * \\
(0.009)\end{array}$ & & & $\begin{array}{c}0.007 \\
(0.021)\end{array}$ & \\
\hline$\%$ Negative & & & $\begin{array}{l}-0.056 \\
(0.045)\end{array}$ & & & $\begin{array}{c}0.063^{* *} \\
(0.028)\end{array}$ & & & $\begin{array}{c}0.035^{* * *} \\
(0.013)\end{array}$ & & & $\begin{array}{c}0.019 \\
(0.020)\end{array}$ \\
\hline Surprise & $\begin{array}{c}0.604 \\
(0.737)\end{array}$ & $\begin{array}{c}0.399 \\
(0.760)\end{array}$ & $\begin{array}{c}0.738 \\
(0.809)\end{array}$ & $\begin{array}{l}-0.027 \\
(0.744)\end{array}$ & $\begin{array}{c}0.100 \\
(0.742)\end{array}$ & $\begin{array}{l}-0.119 \\
(0.755)\end{array}$ & $\begin{array}{c}0.044 \\
(0.522)\end{array}$ & $\begin{array}{c}0.137 \\
(0.488)\end{array}$ & $\begin{array}{l}-0.070 \\
(0.519)\end{array}$ & $\begin{array}{l}-0.635 \\
(0.639)\end{array}$ & $\begin{array}{l}-0.562 \\
(0.635)\end{array}$ & $\begin{array}{l}-0.701 \\
(0.637)\end{array}$ \\
\hline $\mathrm{N}$ & 37 & 37 & 37 & 109 & 109 & 109 & 107 & 107 & 107 & 109 & 109 & 109 \\
\hline$r^{2}$ & 0.24 & 0.25 & 0.23 & 0.08 & 0.09 & 0.06 & 0.13 & 0.09 & 0.15 & 0.03 & 0.03 & 0.04 \\
\hline $\mathrm{F}$ & 3.2 & 3.54 & 2.56 & 1.91 & 1.97 & 1.45 & 1.28 & 1.08 & 1.24 & 0.59 & 0.69 & 0.62 \\
\hline
\end{tabular}

Note: The above panel examines the relationship between Bitcoin returns and news headlines, while controlling for macroeconomic surprises. Panel $\mathrm{C}$ examines the relationship between Bitcoin returns and news headlines, while controlling for macroeconomic surprises and changes in the economic variables themselves.Regressions include day-of-the-week dummys which are not reported. $\mathrm{N}$ represents the total number of observations while standard errors are presented in parentheses. ${ }^{*}$ denotes significance at the $5 \%$ level; ${ }^{* *}$ denotes significance at the $1 \%$ level; $* * *$ denotes significance at the $0.01 \%$ level. 
Table 8: The effect of news stories on Bitcoin returns, controlling for macroeconomic surprises

\begin{tabular}{|c|c|c|c|c|c|c|c|c|c|c|c|c|}
\hline & \multicolumn{3}{|c|}{ GDP } & \multicolumn{3}{|c|}{ Unemployment } & \multirow{2}{*}{\multicolumn{3}{|c|}{ Durable Goods }} & \multicolumn{3}{|c|}{ CPI } \\
\hline & $(1)$ & $(2)$ & $(3)$ & $(4)$ & $(5)$ & $(6)$ & & & & $(10)$ & $(11)$ & $(12)$ \\
\hline News Index & $\begin{array}{l}0.039^{*} \\
(0.020)\end{array}$ & & & $\begin{array}{c}-0.039^{* * *} \\
(0.014)\end{array}$ & & & $\begin{array}{c}-0.018^{* * *} \\
(0.007)\end{array}$ & & & $\begin{array}{c}-0.002 \\
(0.011)\end{array}$ & & \\
\hline \%Positive & & $\begin{array}{l}0.075^{*} \\
(0.038)\end{array}$ & & & $\begin{array}{c}-0.071^{* * * *} \\
(0.026)\end{array}$ & & & $\begin{array}{c}-0.019 * \\
(0.009)\end{array}$ & & & $\begin{array}{c}0.009 \\
(0.021)\end{array}$ & \\
\hline \%Negative & & & $\begin{array}{l}-0.055 \\
(0.046)\end{array}$ & & & $\begin{array}{c}0.066^{* *} \\
(0.028)\end{array}$ & & & $\begin{array}{c}0.036^{* * *} \\
(0.013)\end{array}$ & & & $\begin{array}{c}0.016 \\
(0.020)\end{array}$ \\
\hline Surprise & $\begin{array}{c}-1.573 \\
(1.728)\end{array}$ & $\begin{array}{l}-1.821 \\
(1.683)\end{array}$ & $\begin{array}{c}-1.415 \\
(1.834)\end{array}$ & $\begin{array}{c}-1.854 \\
(1.759)\end{array}$ & $\begin{array}{c}-1.640 \\
(1.7540\end{array}$ & $\begin{array}{c}-1.984 \\
(1.783)\end{array}$ & $\begin{array}{c}0.663 \\
(0.595)\end{array}$ & $\begin{array}{c}0.676 \\
(0.562)\end{array}$ & $\begin{array}{c}0.602 \\
(0.633)\end{array}$ & $\begin{array}{l}-1.193 \\
(0.757)\end{array}$ & $\begin{array}{c}-1.182^{*} \\
(0.757)\end{array}$ & $\begin{array}{l}-1.182 \\
(0.754)\end{array}$ \\
\hline Change & $\begin{array}{c}2.883 \\
(1.874)\end{array}$ & $\begin{array}{l}2.938^{*} \\
(1.798)\end{array}$ & $\begin{array}{c}2.847 \\
(1.965)\end{array}$ & $\begin{array}{c}14.349 \\
(12.518)\end{array}$ & $\begin{array}{c}13.680 \\
(12.500)\end{array}$ & $\begin{array}{c}14.606 \\
(12.656)\end{array}$ & $\begin{array}{c}-0.167 \\
(0.115)\end{array}$ & $\begin{array}{c}-0.145 \\
(0.111)\end{array}$ & $\begin{array}{c}-0.182 \\
(0.131)\end{array}$ & $\begin{array}{c}3.415 \\
(3.028)\end{array}$ & $\begin{array}{c}3.771 \\
(3.035)\end{array}$ & $\begin{array}{c}2.953 \\
(3.022)\end{array}$ \\
\hline $\mathrm{N}$ & 37 & 37 & 37 & 109 & 109 & 109 & 107 & 107 & 107 & 109 & 109 & 109 \\
\hline$r^{2}$ & 0.24 & 0.25 & 0.24 & 0.10 & 0.10 & 0.08 & 0.14 & 0.10 & 0.16 & 0.03 & 0.04 & 0.05 \\
\hline $\mathrm{F}$ & 2.77 & 3.37 & 2.5 & 1.8 & 1.82 & 1.43 & 1.36 & 1.11 & 1.31 & 0.59 & 0.69 & 0.57 \\
\hline
\end{tabular}

Note: The above panel examines the relationship between Bitcoin returns and news headlines, while controlling for macroeconomic surprises and changes in the economic variables themselves.Regressions include day-of-the-week dummys which are not reported. $\mathrm{N}$ represents the total number of observations while standard errors are presented in parentheses. ${ }^{*}$ denotes significance at the $5 \%$ level; ${ }^{* *}$ denotes significance at the $1 \%$ level; $* * *$ denotes significance at the $0.01 \%$ level. 
Table 9: The effect of news stories on Bitcoin returns, controlling for macroeconomic surprises in different states of the business cycle.

\begin{tabular}{|c|c|c|c|c|c|c|c|c|c|c|c|c|}
\hline & \multicolumn{3}{|c|}{ GDP } & \multicolumn{3}{|c|}{ Unemployment } & \multicolumn{3}{|c|}{ Durable Goods } & \multicolumn{3}{|c|}{ CPI } \\
\hline & (1) & $(2)$ & (3) & (4) & $(5)$ & (6) & (7) & $(8)$ & (9) & (10) & $(11)$ & (12) \\
\hline News Index & $\begin{array}{c}0.037 \\
(0.031)\end{array}$ & & & $\begin{array}{c}-0.034^{* *} \\
(0.014)\end{array}$ & & & $\begin{array}{c}-0.021^{* * *} \\
(0.007)\end{array}$ & & & $\begin{array}{c}-0.002 \\
(0.011)\end{array}$ & & \\
\hline \%Positive & & $\begin{array}{c}0.079 \\
(0.060)\end{array}$ & & & $\begin{array}{c}-0.056^{* *} \\
(0.026)\end{array}$ & & & $\begin{array}{c}-0.026^{* *} \\
(0.010)\end{array}$ & & & $\begin{array}{c}0.012 \\
(0.022)\end{array}$ & \\
\hline$\%$ Negative & & & $\begin{array}{c}0.043 \\
(0.058)\end{array}$ & & & $\begin{array}{c}0.053^{*} \\
(0.027)\end{array}$ & & & $\begin{array}{c}0.036^{* * *} \\
(0.014)\end{array}$ & & & $\begin{array}{c}0.018 \\
(0.021)\end{array}$ \\
\hline Low & $\begin{array}{c}1.256 \\
(2.057)\end{array}$ & $\begin{array}{c}1.357 \\
(2.034)\end{array}$ & $\begin{array}{c}0.900 \\
(2.033)\end{array}$ & $\begin{array}{c}-2.650^{* *} \\
(1.259)\end{array}$ & $\begin{array}{c}-2.506^{*} \\
(1.272)\end{array}$ & $\begin{array}{c}-2.874^{* *} \\
(1.256)\end{array}$ & $\begin{array}{c}2.077 \\
(1.376)\end{array}$ & $\begin{array}{l}2.337^{*} \\
(1.413)\end{array}$ & $\begin{array}{c}1.551 \\
(1.320)\end{array}$ & $\begin{array}{l}-1.941 \\
(1.277)\end{array}$ & $\begin{array}{c}-1.687 \\
(1.240)\end{array}$ & $\begin{array}{c}-2.180^{*} \\
(1.3430\end{array}$ \\
\hline Medium & $\begin{array}{c}0.085 \\
(1.319)\end{array}$ & $\begin{array}{l}-0.513 \\
(1.314)\end{array}$ & $\begin{array}{c}0.154 \\
(1.527)\end{array}$ & $\begin{array}{c}0.874 \\
(0.983)\end{array}$ & $\begin{array}{l}1.017 \\
(0.975)\end{array}$ & $\begin{array}{c}0.812 \\
(0.997)\end{array}$ & $\begin{array}{c}0.456 \\
(0.635)\end{array}$ & $\begin{array}{c}0.493 \\
(0.656)\end{array}$ & $\begin{array}{c}0.259 \\
(0.655)\end{array}$ & $\begin{array}{c}-1.646^{* *} \\
(0.754)\end{array}$ & $\begin{array}{c}-1.662^{* *} \\
(0.753)\end{array}$ & $\begin{array}{r}-1.670^{* *} \\
(0.751)\end{array}$ \\
\hline High & $\begin{array}{c}1.785 \\
(1.434)\end{array}$ & $\begin{array}{c}1.754 \\
(1.527)\end{array}$ & $\begin{array}{l}2.209^{*} \\
(1.332)\end{array}$ & $\begin{array}{c}2.035 \\
(1.560)\end{array}$ & $\begin{array}{c}1.970 \\
(1.563)\end{array}$ & $\begin{array}{c}2.151 \\
(1.566)\end{array}$ & $\begin{array}{c}-0.839^{* *} \\
(0.395)\end{array}$ & $\begin{array}{c}-0.697^{* *} \\
(0.338)\end{array}$ & $\begin{array}{c}-0.766^{*} \\
(0.439)\end{array}$ & $\begin{array}{c}2.002 \\
(1.318)\end{array}$ & $\begin{array}{l}2.179^{*} \\
(1.291)\end{array}$ & $\begin{array}{c}1.912 \\
(1.332)\end{array}$ \\
\hline $\mathrm{N}$ & 37 & 37 & 37 & 109 & 109 & 109 & 107 & 107 & 107 & 109 & 109 & 109 \\
\hline$r^{2}$ & 0.241 & 0.256 & 0.213 & 0.148 & 0.147 & 0.139 & 0.165 & 0.136 & 0.175 & 0.092 & 0.096 & 0.102 \\
\hline $\mathrm{F}$ & 6.31 & 6.44 & 5.01 & 3.65 & 3.61 & 3.38 & 1.48 & 1.58 & 1.27 & 1.62 & 1.75 & 1.6 \\
\hline
\end{tabular}

ificance at the $1 \%$ level; $* *$ umber of observations while standard 
Table 10: The effect of news stories on Bitcoin returns, controlling for political bias and macroeconomic surprises.

\begin{tabular}{|c|c|c|c|c|c|c|c|c|c|c|c|c|}
\hline & \multicolumn{3}{|c|}{ GDP } & \multicolumn{3}{|c|}{ Unemployment } & \multicolumn{3}{|c|}{ Durable Goods } & \multicolumn{3}{|c|}{ CPI } \\
\hline & (1) & $(2)$ & (3) & (4) & $(5)$ & (6) & (7) & $(8)$ & $(9)$ & $(10)$ & $(11)$ & $(12)$ \\
\hline News Index & $\begin{array}{c}0.039^{*} \\
(0.020)\end{array}$ & & & $\begin{array}{c}-0.038^{* *} \\
(0.014)\end{array}$ & & & $\begin{array}{c}-0.018^{* * *} \\
(0.007)\end{array}$ & & & $\begin{array}{c}-0.002 \\
(0.011)\end{array}$ & & \\
\hline \% Positive & & $\begin{array}{l}0.075^{*} \\
(0.041)\end{array}$ & & & $\begin{array}{c}-0.070^{* * *} \\
(0.026)\end{array}$ & & & $\begin{array}{c}-0.019^{* * *} \\
(0.007)\end{array}$ & & & $\begin{array}{c}0.008 \\
(0.021)\end{array}$ & \\
\hline$\%$ Negative & & & $\begin{array}{c}-0.057 \\
(0.046)\end{array}$ & & & $\begin{array}{c}0.064^{* *} \\
(0.028)\end{array}$ & & & $\begin{array}{r}0.036^{* *} \\
(0.014)\end{array}$ & & & $\begin{array}{r}0.015 \\
(0.020)\end{array}$ \\
\hline Surprise & $\begin{array}{c}0.602 \\
(0.737)\end{array}$ & $\begin{array}{c}0.398 \\
(0.760)\end{array}$ & $\begin{array}{c}0.738 \\
(0.810)\end{array}$ & $\begin{array}{l}-0.028 \\
(0.744)\end{array}$ & $\begin{array}{c}0.099 \\
(0.742)\end{array}$ & $\begin{array}{l}-0.121 \\
(0.756)\end{array}$ & $\begin{array}{c}0.040 \\
(0.525)\end{array}$ & $\begin{array}{c}0.136 \\
(0.489)\end{array}$ & $\begin{array}{c}-0.079 \\
(0.524)\end{array}$ & $\begin{array}{c}-0.621 \\
(0.638)\end{array}$ & $\begin{array}{c}-0.557 \\
(0.635)\end{array}$ & $\begin{array}{l}-0.681 \\
(0.637)\end{array}$ \\
\hline $\mathrm{N}$ & 37 & 37 & 37 & 109 & 109 & 109 & 107 & 107 & 107 & 109 & 109 & 109 \\
\hline$r^{2}$ & 0.237 & 0.221 & 0.209 & 0.082 & 0.085 & 0.063 & 0.134 & 0.093 & 0.152 & 0.029 & 0.030 & 0.036 \\
\hline $\mathrm{F}$ & 3.14 & 3.53 & 2.51 & 1.89 & 1.96 & 1.42 & 1.27 & 1.08 & 1.24 & 0.6 & 0.7 & 0.6 \\
\hline
\end{tabular}

Note: The table shows the results of 12 regressions in which the dependent variable is Bitcoin returns. News Index* is calculated using the residuals from a regression analysis of News Index and an indicator variable representing the presence of a Republican President. \%Positive* and \%Negative* are calculated in a similar way using the percentage of positive and negative stories respectively. Regressions include day-of-the-week dummys which are not reported. $\mathrm{N}$ represents the total number of observations while standard errors are presented in parentheses. * denotes significance at the $5 \%$ level; $* *$ denotes significance at the $1 \%$ level; *** denotes significance at the $0.01 \%$ level 
Table 11: The effect of market activity on the number of news stories.

\begin{tabular}{lcccc}
\hline & GDP & Unemployment & Durable Goods & CPI \\
\hline BTC & 0.427 & -0.532 & 0.843 & 0.318 \\
& $(1.916)$ & $(1.210)$ & $(0.620)$ & $(0.615)$ \\
$\mathrm{N}$ & 37 & 109 & 110 & 109 \\
$r^{2}$ & 0.002 & 0.002 & 0.021 & 0.003 \\
$\mathrm{~F}$ & 0.05 & 0.19 & 1.85 & 0.27 \\
\hline
\end{tabular}

Note: The table shows the results of four different regressions in which the dependent variable is the number of stories related to each of the four economic variables. BTC represents the absolute value of Bitcoin returns. N represents the total number of observations while standard errors are presented in parentheses. * denotes significance at the $5 \%$ level; ${ }^{* *}$ denotes significance at the $1 \%$ level; $* * *$ denotes significance at the $0.01 \%$ level 